\title{
Effect of Bone Morphogenetic Protein-2 and Doxycycline on the Differentiation of Osteoprogenitors from Human Femoral Bone
}

\author{
Aline Eglence ${ }^{1}$, Nigel Colterjohn $^{\dagger, 2}$, Wilhelmina CM Duivenvoorden ${ }^{1,3}$, Michelle Ghert ${ }^{1,2}$ and \\ Gurmit Singh" \\ ${ }^{1}$ Juravinski Cancer Centre, 699 Concession Street, Hamilton, Ontario, L8V 5C2, Canada \\ ${ }^{2}$ Department of Surgery, McMaster University, 1280 Main Street W, Hamilton, Ontario, L8N 3Z5, Canada \\ ${ }^{3}$ Department of Pathology and Molecular Medicine, McMaster University, 1280 Main Street W, Hamilton, Ontario, L8N \\ 3Z5, Canada
}

\begin{abstract}
The purpose of this investigation was to evaluate the effects of bone morphogenetic protein-2 (BMP-2) and doxycycline on the in vitro differentiation of osteoprogenitor cells isolated from human femoral cancellous bone. The differentiation of osteoprogenitors into bone-forming osteoblasts was evaluated by alkaline phosphatase activity, osteocalcin gene expression, and the number of Von Kossa-positive bone nodules. Treatment of osteoprogenitors with BMP-2, at all concentrations tested, and doxycycline, at 10 and $50 \mu \mathrm{M}$, significantly increased the number of mineralized bone nodules and coincided with expression of osteocalcin. In conclusion, doxycycline at 10 and $50 \mu \mathrm{M}$ had similar stimulatory osteoinductive effects as BMP-2 and could thus be considered as an alternative agent to BMP-2.
\end{abstract}

\section{${ }^{\dagger}$ In Memory of Dr. Colterjohn, a Talented and Supportive Colleague who we lost during the Final Stages of this Project}

\section{INTRODUCTION}

Bone is a highly organized tissue composed of different types of cells, interacting in an organic matrix of mineralized hydroxyapatite and amorphous calcium phosphate crystals [1]. The principle bone-forming cells are the osteoblasts which are derived from mesenchymal stem cells. Mesenchymal stem cells have been isolated from periosteum, cancellous bone, cortical bone and bone marrow [2, 3]. Osteoblastogenesis, the differentiation of preosteoblasts to the terminally differentiated osteoblastic phenotype, can be divided into three stages, namely proliferation, matrix development, and maturation and mineralization. The markers most frequently used to follow the differentiation process of osteoblasts include type I collagen, alkaline phosphatase (ALP), and osteocalcin (OCN). In general, the markers type I collagen and ALP are considered early markers of osteoblastogenesis, while OCN, which is closely associated with mineralization, is considered an advanced marker [4] and specific to bone [5]. The most reliable indicator of differentiation of osteoprogenitors to the terminal osteoblastic phenotype is mineralization [6].

Bone morphogenetic proteins (BMPs) play critical roles in osteoblast differentiation. BMPs belong to the transforming growth factor superfamily and act to differentiate early osteoblastic cells to the non-dividing terminally

*Address correspondence to this author at the Juravinski Cancer Centre, 699 Concession Street, Hamilton, Ontario, L8V 5C2, Canada; E-mail: gurmit.singh@jcc.hhsc.ca differentiated phenotype via a Smad-mediated pathway [7]. BMP-2 specifically has been shown to induce osteoblast differentiation [8-10]. In numerous clinical studies, BMP-2 has been demonstrated to stimulate the differentiation of osteoprogenitors and is employed as an effective alternative to autogenous bone graft, which, although the current gold standard for bone repair, is also associated with significant clinical morbidity at the donor site [11-14].

Tetracyclines, a well-characterized family of antibiotics, may have specific therapeutic value in the treatment of bone diseases, since they have tremendous affinity for mineralized bone matrix. Tetracyclines have been shown to restore or maintain bone; in diabetic and ovariectomized rats, minocycline can prevent cancellous bone loss by both inhibiting bone resorption and increasing osteoblastic activity [15-18]. We have previously shown that doxycycline decreases tumor burden in a mouse model for human breast cancer bone metastasis and increases bone formation parameters, such as osteoid volume, osteoid surface and number of osteoblasts per bone surface [19]. Doxycycline has also been shown to inhibit bone degradation in human periodontal disease [20] and to reverse the effects of ovariectomy on load causing fracture of the femoral neck in mice [21]. Doxycycline-loaded biodegradable tissue regenerating membranes inserted into bone defects in a canine model have been shown to increase bone parameters, such as height and area, significantly when compared to non-treated membranes [22].

In this study, we comparatively investigated the effects of BMP-2 and doxycycline on the differentiation of human 
osteoprogenitor cells isolated from human cancellous bone from the femoral neck using ALP activity, expression of OCN, and mineralization as markers of osteoblast differentiation.

\section{MATERIALS AND METHODOLOGY}

\section{Reagents}

Standard medium (SM) consisted of alpha minimal essential medium ( $\alpha$-MEM) supplemented with antibiotics/ antimycotics (100 units/ml penicillin sodium, $100 \mu \mathrm{g} / \mathrm{ml}$ streptomycin sulfate and $0.3 \mu \mathrm{g} / \mathrm{ml}$ amphotericin $\mathrm{B}$, and 50 $\mu \mathrm{g} / \mathrm{ml}$ gentamycin), L-glutamine $(200 \mathrm{mM})$ and $10 \%$ Fetal Bovine Serum (FBS). Osteogenic medium (OM) consisted of SM supplemented with $10 \mathrm{mM} \beta$-glycerophosphate and 50 $\mu \mathrm{g} / \mathrm{ml} L$-ascorbic acid (Sigma-Aldrich, Oakville ON, Canada) to contain the minimum requirements for differentiation to osteoblastic phenotype. All tissue culture media and reagents were obtained from Invitrogen Life Technologies (Burlington, ON, Canada). Recombinant human BMP-2 (R\&D systems, Minneapolis, MN) was dissolved in filter-sterilized $4 \mathrm{mM}$ hydrochloric acid containing $0.1 \%$ bovine serum albumin (Sigma-Aldrich) at a concentration of $10 \mu \mathrm{g} / \mathrm{ml}$ and stored at $-20{ }^{\circ} \mathrm{C}$. OM containing 1,10 or $100 \mathrm{ng} / \mathrm{ml}$ of BMP-2 was prepared freshly. Doxycycline (Sigma-Aldrich) was prepared as a 5 $\mathrm{mM}$ stock solution using filter-sterilized distilled water. This stock solution was used to prepare OM containing 10, 50 and $100 \mu \mathrm{M}$ doxycycline, which were prepared freshly each time.

\section{Cell Isolation and Primary Cell Culture}

Human cancellous bone was harvested from the femoral neck of total hip replacement surgery patients $(n=8,5$ women, 3 men, age=76.7 \pm 7.8 ). Patients provided signed consent and approval for this study was obtained from the Hamilton Research Ethics Board. Cells were isolated from cancellous bone chips (2-4 grams each). Bone samples were cut into $3 \times 3 \mathrm{~mm}$ chips using bone cutters and rongeurs, washed twice with phosphate buffer saline (PBS) and placed in red blood cell lysis buffer (BioLegend, San Diego CA) for $15 \mathrm{~min}$.

Bone chips ( $1 \mathrm{~g}$ total) were placed in $50 \mathrm{ml}$ Falcon tubes and $3 \mathrm{ml}$ of collagenase (2000 units/ml; Invitrogen Life Technologies) was added and allowed to incubate for $10 \mathrm{~min}$ at $37^{\circ} \mathrm{C}$. The collagenase was replaced with $6 \mathrm{ml}$ of fresh collagenase solution and incubated for $2 \mathrm{~h}$ and $30 \mathrm{~min}$ after which the remaining bone chips were filtered out of solution using a $0.5 \mathrm{~mm}$ sieve. The cell suspension was centrifuged for $7 \mathrm{~min}$ at $1500 \mathrm{rpm}$. The supernatant was aspirated and replaced with 2-4 $\mathrm{ml}$ of SM and the number of cells was determined using a hemocytometer. Cells were grown for 9 days in SM to reach $70 \%$ confluence $\left(2.5 \times 10^{6}\right.$ cells per T75 flask). Media was changed 3 times per week and cells were maintained at $37{ }^{\circ} \mathrm{C}$ in a humidified atmosphere with $5 \%$ $\mathrm{CO}_{2}$. On day 9, cells were detached with $0.05 \%$ trypsin. Cells were then plated at a seeding density of $2 \times 10^{5}$ cells per well in a 6-well plate in OM containing BMP-2 or doxycycline. BMP-2 concentrations used were 1, 10 and 100 $\mathrm{ng} / \mathrm{ml}$, whereas doxycycline was used at endconcentrations of 10,50 and $100 \mu \mathrm{M}$ in the medium. SM was used as a negative control (no addition of osteoinductive factors). OM alone was also used as a control.

\section{Alkaline Phosphatase Activity and Staining}

Cell cultures were processed for alkaline phosphatase activity after one and eight days of treatment with BMP-2 or doxycycline. Intracellular ALP activity was measured using the Enzolyte pNNP colorimetric kit from AnaSpec using cell lysate samples. Briefly, cells were washed three times using PBS, and lysed using $500 \mu \mathrm{l}$ of lysis buffer containing $0.5 \%$ Triton X-100 and three freeze-thaw cycles. Lysates were also prepared from cells grown in OM and SM as controls. Fifty $\mu l$ of sample or standard (calf intestine alkaline phosphatase at concentrations ranging from $0.00128 \mathrm{ng} / \mathrm{ml}$ to $0.2 \mu \mathrm{g} / \mathrm{ml}$ ) was added to a well of 96-well plate containing $50 \mu 1$ of $p$ nitrophenyl phosphate assay buffer. After 30-min incubation at $37^{\circ} \mathrm{C}$, the absorbance at $405 \mathrm{~nm}$ was measured using a PowerwaveXS (Biotek) microplate spectrophotometer. Protein in the cell lysates was determined using the micro BCA kit (Pierce). Data were expressed as a ratio of ALP activity per $\mu \mathrm{g}$ of protein and performed in duplicate (mean \pm SEM).

Alkaline phosphatase staining was performed according to the Fast Blue RR protocol from the alkaline phosphatase kit (Sigma-Aldrich) using cells fixed in warm citratebuffered acetone $(60 \%)$ for 30 seconds.

\section{Reverse Transcriptase-Polymerase Chain Reaction (RT- PCR)}

Total RNA was isolated after one and eight days from treated and control cells cultured in a 6-well plate using the Qiagen RNeasy Mini Kit (Qiagen, Mississauga, ON Canada) according to the manufacturer's instructions. Complementary DNA (cDNA) was made using a Superscript III RTPCR kit (Invitrogen Life Technologies) with $500 \mathrm{ng}$ of total RNA using random primers. One $\mu$ l of RNase $\mathrm{H}$ was added and incubated for $20 \mathrm{~min}$ at $37{ }^{\circ} \mathrm{C}$. OCN primers (SigmaAldrich) have been used in various other studies [18-20]. The primer sequences used were: forward 5'ATGAGA GCCCTCACACTCCTC'3 and reverse 5'GCCGTAGAAGC GCCGATAGGC'3 to generate a 297 base pair (bp) PCRproduct.

Sense and antisense primers $(0.2 \mu \mathrm{M})$ were mixed with PCR buffer $(0.2 \mathrm{mM}$ dNTP mix, $1 \mathrm{mM} \mathrm{MgCl}$ ) $2 \mu \mathrm{l}$ cDNA and 0.04 units Taq DNA polymerase (Invitrogen Life Technologies) in a final volume of $50 \mu$ l. The PCR reaction was performed in a thermal cycler (PerkinElmer, Waltham MA) for 45 cycles. Conditions were denaturation at $94{ }^{\circ} \mathrm{C}$ for $15 \mathrm{~s}$; annealing at $65^{\circ} \mathrm{C}$ for $30 \mathrm{~s}$; and extension at $72{ }^{\circ} \mathrm{C}$ for $30 \mathrm{~s}$. Expression of glyceraldehyse-3-phosphate dehydrogenase (GAPDH) served as a control. The primer sequences were sense 5'ATGTTCCAATATGATTCC'3 and antisense 5'ACGATACCAAAGTTGTCA'3 (Sigma-Aldrich) to generate a 375 bp PCR product. The PCR conditions were 35 cycles of denaturation at $94{ }^{\circ} \mathrm{C}$ for $15 \mathrm{~s}$, annealing at $55{ }^{\circ} \mathrm{C}$ for $30 \mathrm{~s}$ and extension at $72{ }^{\circ} \mathrm{C}$ for $30 \mathrm{~s}$. PCR products were resolved by electrophoresis in a $1.2 \%$ agarose gel containing $0.5 \mu \mathrm{g} / \mathrm{ml}$ ethidium bromide. 


\section{Von Kossa Staining}

After eight days of treatment with either BMP-2 or doxycycline, cell cultures were processed for Von Kossa staining to assess mineralized bone nodule production following the protocol by Bhargava et al. [23]. The bone nodules were analyzed under a phase-contrast microscope for mineralization. Using an England Finder Graticule (Ted Pella Inc., Redding CA), the number of nodules with a diameter equal to or greater than $25 \mu \mathrm{m}$ was determined.

\section{Statistical Analysis}

The mineralization and alkaline phosphatase activity data were tested for statistical differences using one-way ANOVA followed by post-hoc Dunnett's test using Minitab
14 software . Differences between means were considered significant at $\mathrm{p}<0.05$.

\section{RESULTS}

Human cancellous bone from the femoral neck of total hip replacement surgery patients $(n=8)$ using collagenase yielded on average $4.99 \pm 0.92$ million osteoprogenitor cells per gram of bone. When the osteoprogenitor quality of the cells was assessed, we found that cells isolated from all eight donors stained positive for alkaline phosphatase (Fig. 1), an early marker for osteoblasts [4]. ALP activity was also measured using cell lysates from osteoprogenitor cells after one and eight days of treatment with either BMP-2 or doxycycline using $p$-nitrophenyl phosphate as a substrate. Treatment with 10 and $50 \mu \mathrm{M}$ doxycycline for 1 day led to

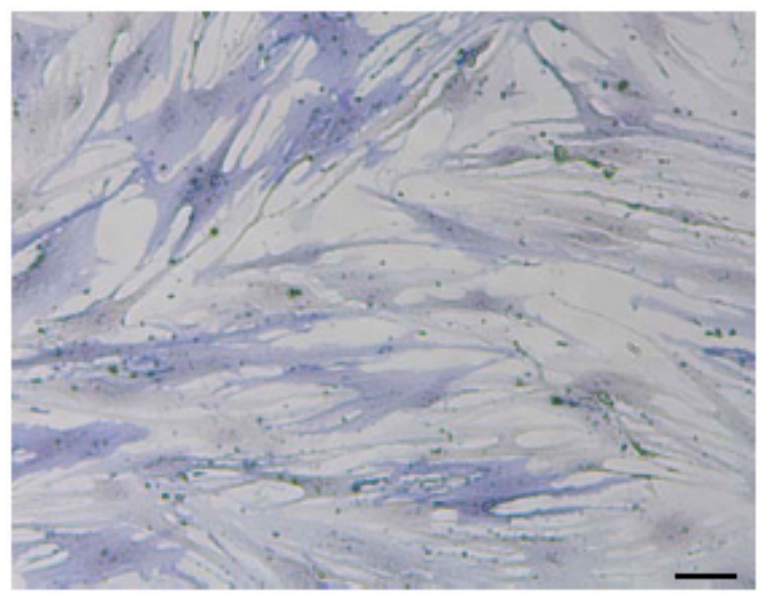

Fig. (1). Alkaline phosphatase staining of human osteoprogenitors.

Micrograph of alkaline phosphatase-stained human osteoprogenitor cell culture. Osteoprogenitor cells, isolated using collagenase and expanded for 9 days in standard medium were plated at a density of $2 \times 10^{5}$ cells per well of a 6-well plate and cultured for an additional eight days in osteogenic medium. (Magnification, 100x; scale bar $=60 \mu \mathrm{m}$ ).

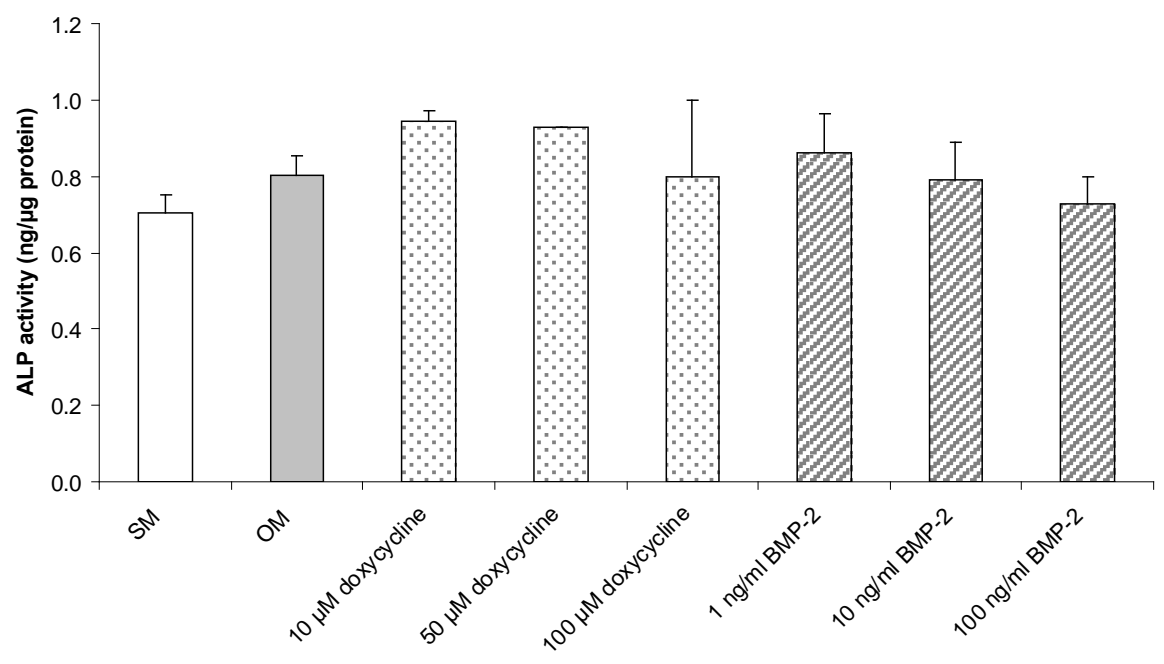

Fig. (2). Alkaline phosphatase activity.

The activity of alkaline phosphatase after treatment with bone morphogenic protein-2 (BMP-2) or doxycycline was determined. Human osteoprogenitor cells were isolated from femoral neck using collagenase digestion. After expansion for 9 days in standard medium (SM), cells were plated at a density of $2 \times 10^{5}$ cells per well of a 6-well plate and incubated for one day in the presence or absence of BMP-2 or doxycycline at different concentrations. The alkaline phosphatase activity in the cell lysates was determined using $p$-nitrophenol phosphate as a substrate and calculated using a calf intestine alkaline phosphatase standard curve and adjusted for total protein content. Results represent data obtained from at least two independent experiments carried out in duplicate. Data after treatment were not statistically significantly different from OM alone by one-way ANOVA. 
A
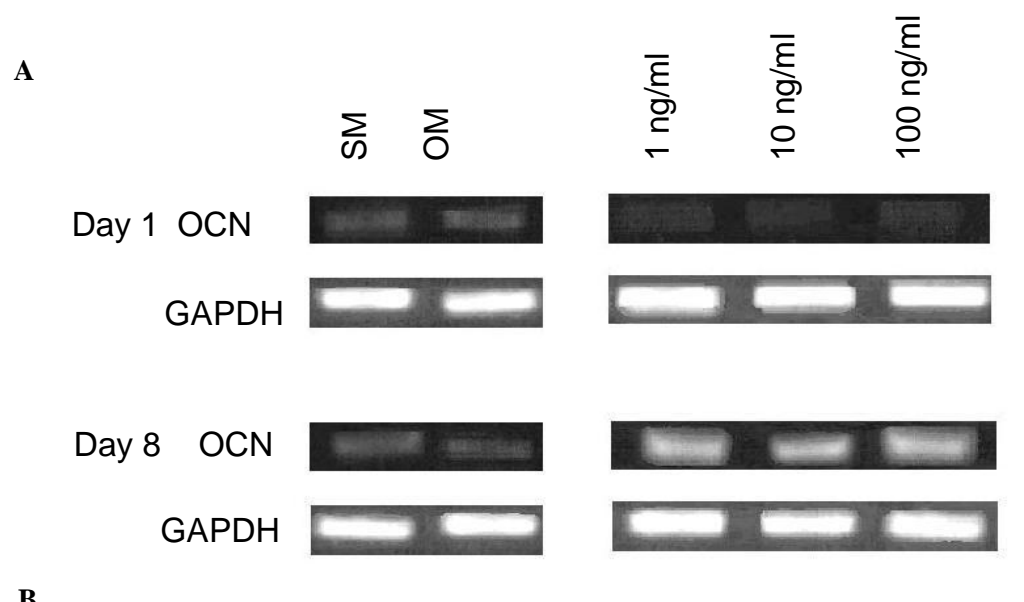

B

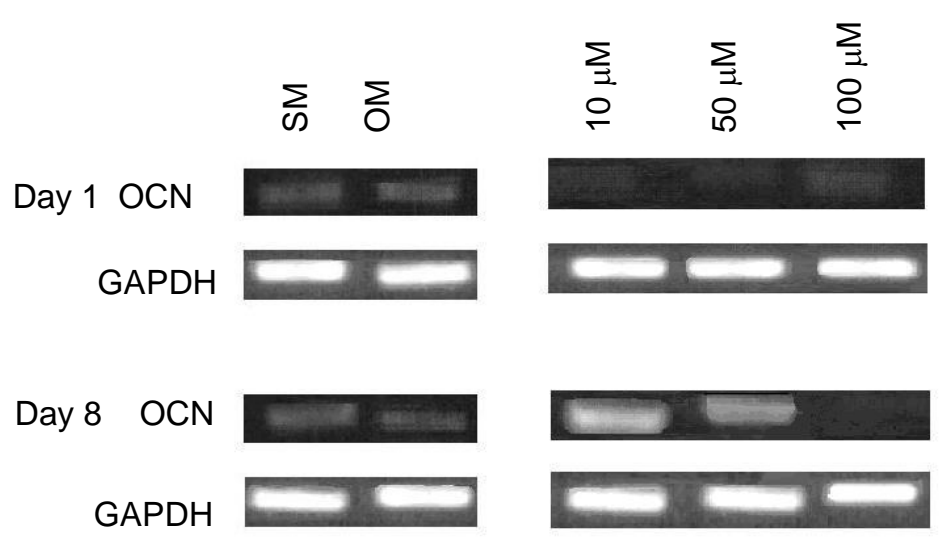

Fig. (3). Osteocalcin expression.

Expression of osteocalcin (OCN) as determined by reverse transcriptase-polymerase chain reaction (RT-PCR) in human osteoprogenitor cell cultures after treatment with bone morphogenic protein-2 (BMP-2) (A) or doxycycline (B) at various concentrations. Human osteoprogenitor cells, isolated using collagenase digestion and expanded for 9 days in standard medium (SM), were plated at a density of $2 \times 10^{5}$ cells per well of a 6-well plate. After one and eight days, total RNA was extracted from the cells and amplified by RT-PCR. The controls included cells cultured in osteogenic medium (OM) and SM, and glyceraldehyde-3-phosphate dehydrogenase (GAPDH) served as control for housekeeping gene expression. Amplified products were separated by agarose gel electrophoresis. OCN was run for 45 cycles; GAPDH for 35 cycles. Results show one typical experiment of three independent experiments performed.

an increase in the amount of ALP activity of 18 and $15 \%$ respectively, when compared to control OM (Fig. 2). Oneway ANOVA test did not show significance $(\mathrm{p}=0.54)$, likely due to insufficient numbers of cells and independent experiments. BMP-2 did also not change ALP activity significantly $(p=0.69)$. At $1 \mathrm{ng} / \mathrm{ml}$ of $B M P-2$, the amount of ALP activity amounted to $107.4 \%$ of control OM. The ALP activity obtained after eight days of treatment (data not shown) was several fold lower than after one day, indicative of ALP being an early marker.

To further determine differentiation of the human osteoprogenitor cells into the mature osteoblastic phenotype, OCN expression was analyzed by RT-PCR. On day 1 and 8 in control groups and day 1 of treatment, negative to weak OCN expression was observed. On day 8 of treatment with BMP-2, expression of OCN was observed at all concentrations (Fig. 3A). On day 8 of doxycycline treatment, OCN was also expressed at the low doxycycline concentrations of 10 and $50 \mu \mathrm{M}$. However, cells treated with $100 \mu \mathrm{M}$ doxycycline showed no expression for OCN (Fig. 3B).
Osteoprogenitor cells were cultured in the presence or absence of BMP-2 or doxycycline in OM for eight days to investigate their effects on bone formation. After staining with Von Kossa, mineralized nodules were microscopically visualized as having a solid black core (Fig. 4). Nodules with a yellow-brownish core representing unmineralized osteoid were also observed (data not shown), but were not included in the counts. Cells grown in the absence of $\beta$ glycerophosphate and ascorbic acid did not show high mineralization activity. The average number of nodules produced by the osteoprogenitor cells in SM amounted to $36.4 \pm 2.6$. Treatment with BMP-2 (Fig. 5) significantly affected the number of mineralized bone nodules when compared to control OM by one-way ANOVA $(\mathrm{p}<0.001)$. BMP-2 at 1, 10 and $100 \mathrm{ng} / \mathrm{ml}$ increased the number of mineralized bone nodules by $42 \%, 83 \%$ and $52 \%$ over OM alone, respectively. At $10 \mathrm{ng} / \mathrm{ml}, \mathrm{BMP}-2$ produced the highest number of nodules. Dunnett's post-hoc tests showed that the difference between the means was significant for all means compared to $\mathrm{OM}(1 \mathrm{ng} / \mathrm{ml}: \mathrm{p}<0.05 ; 10 \mathrm{ng} / \mathrm{ml}$ : $\mathrm{p}<0.001 ; 100 \mathrm{ng} / \mathrm{ml}: \mathrm{p}<0.005)$. Similarly, one-way ANOVA showed that doxycycline treatment resulted in significant 


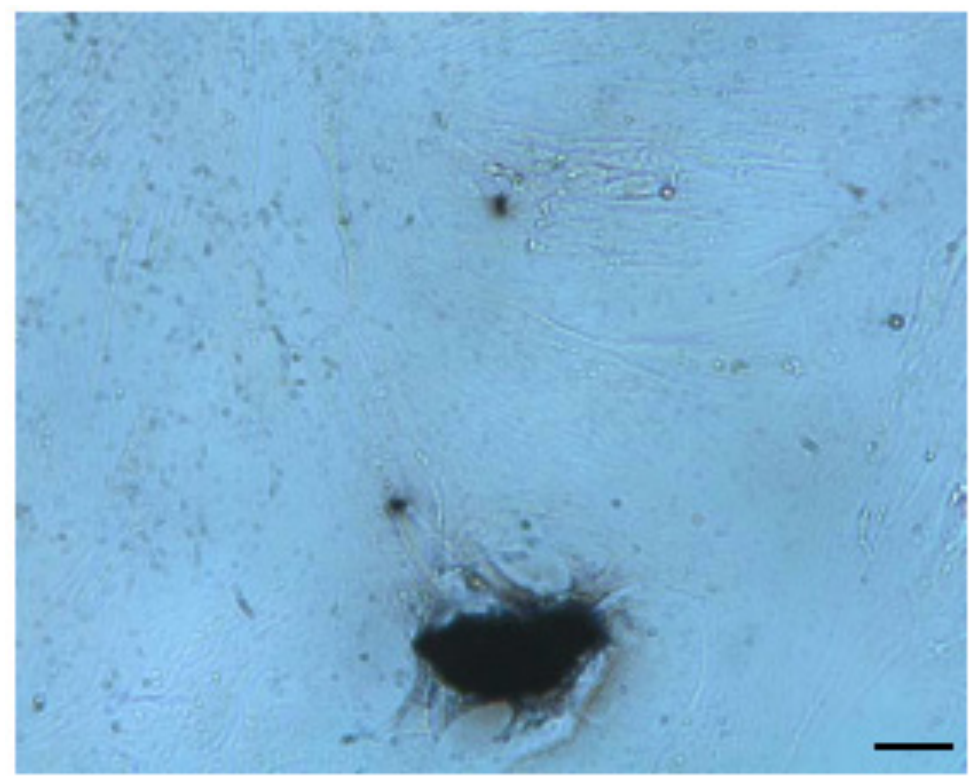

Fig. (4). Von Kossa-stained mineralized nodule.

Micrograph of mineralized bone nodule stained with Von Kossa. Osteoprogenitor cells, isolated using collagenase and expanded for 9 days in standard medium were plated at a density of $2 \times 10^{5}$ cells per well of a 6 -well plate and cultured for an additional eight days in osteogenic medium. (Magnification, 100x; scale bar $=60 \mu \mathrm{m}$ ).

differences $(\mathrm{p}<0.001)$ in mineralization of the osteoprogenitor cells. Doxycycline at $10 \mu \mathrm{M}$ and $50 \mu \mathrm{M}$ significantly increased the number of mineralized bone nodules (post-hoc Dunnett's test $\mathrm{p}<0.001$ and $\mathrm{p}<0.05$, respectively) when compared to untreated control cells. The increases in the bone nodules induced by $10 \mu \mathrm{M}$ and $50 \mu \mathrm{M}$ doxycycline amounted to $86 \%$ and $32 \%$, respectively. Doxycycline at $100 \mu \mathrm{M}$ decreased the nodule formation when compared to control OM. The effects of BMP-2 and doxycycline on the formation of mineralized nodules coincided with OCN expression.

\section{DISCUSSION AND CONCLUSION}

The isolation of osteoprogenitors from cancellous bone, including from the femur, is widely accepted [2, 24, 25]. In this study, we used human cancellous bone harvested from

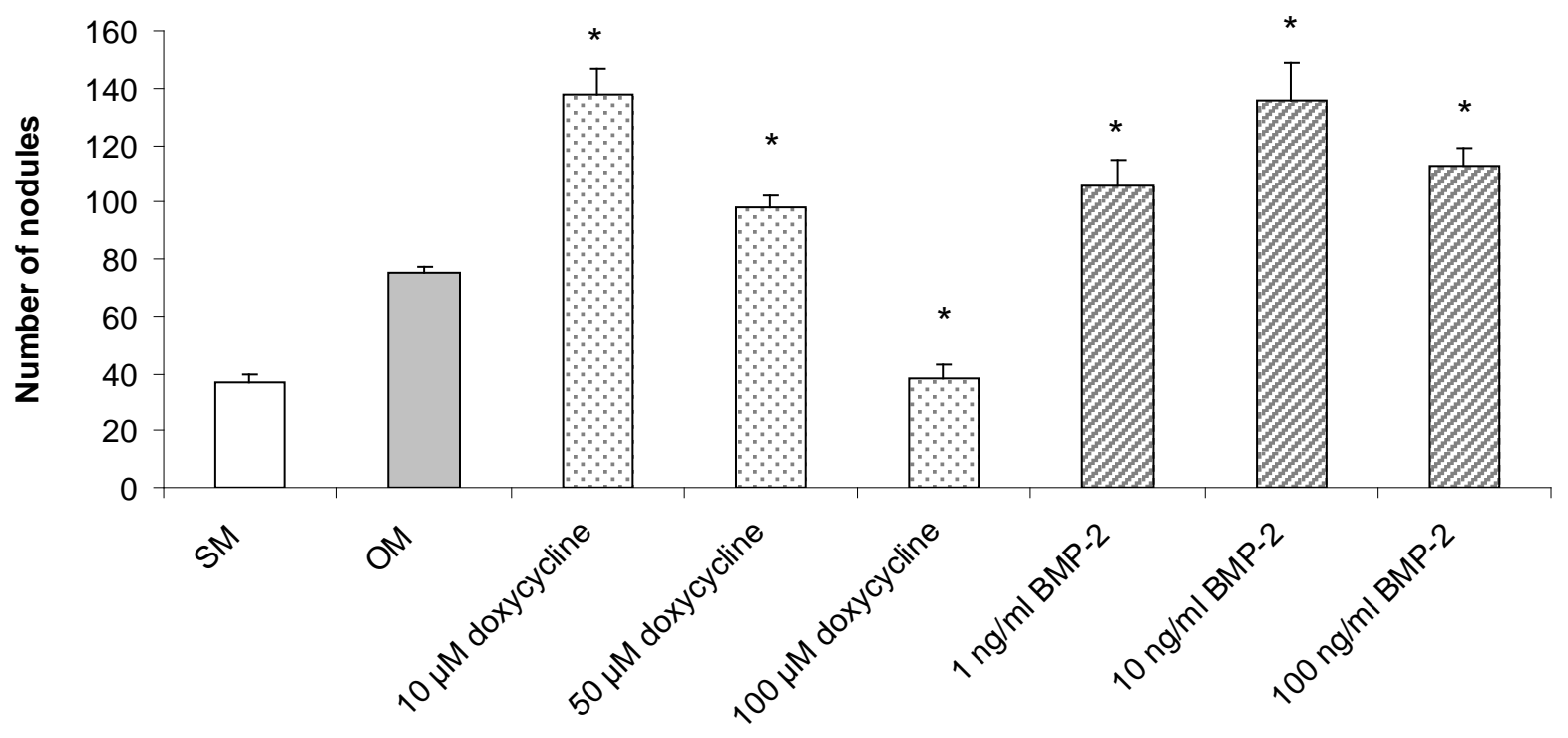

Fig. (5). Bone nodule formation.

The number of mineralized nodules after eight days of treatment with bone morphogenic protein-2 (BMP-2) or doxycycline was determined. Human osteoprogenitor cells were isolated from femoral neck using collagenase digestion. After expansion for 9 days in standard medium (SM), cells were plated at a density of $2 \times 10^{5}$ cells per well of a 6-well plate and incubated for eight days in the presence or absence of BMP2 or doxycycline at different concentrations. The number of mineralized nodules stained with Von Kossa, with a diameter of $>25 \mu \mathrm{m}$, was determined. Results represent data obtained from three independent experiments. * Statistical differences were determined using a one-way ANOVA followed by post-hoc Dunnett's test comparing treatment to OM ( $<<0.05)$. 
the femoral neck digested with collagenase and generated a large number of osteoprogenitor cells with cell yields in the same order of magnitude as reported elsewhere [24, 26]. Enzymatic digestion of trabecular bone has been shown to yield a relatively homogeneous osteoblastic cell population, likely due to the fact that collagenase digestion removes a substantial amount of the connective tissue components [27]. Due to availability and practicality, human bone, whether cancellous or cortical, appears to be most ideal when compared to the alternatives, periosteum and bone marrow aspirates. Cells derived from the periosteum have been shown to possess the highest proliferative capacity and the highest ALP activity when compared to cells obtained from cortical and cancellous bone [2], however, the periosteum is not practical to harvest and the cells appear to dedifferentiate earlier in vitro than cells isolated from cancellous bone [2]. It has been demonstrated that the osteoprogenitors isolated from cancellous bone posses characteristics of mesenchymal stem cells and the potential to differentiate into osteoblasts, chondrocytes and adipocytes $[25,28]$. The femoral neck as a harvesting site is invasive. In our research environment, however, femoral neck samples were readily available through regularly scheduled total hip replacement surgeries without additional morbidity to the patient donor. Cancellous bone from the iliac crest would constitute a less invasive site and has also been shown to be a good source of osteoprogenitors [25].

Both BMP-2 and doxycycline stimulated osteoblastic differentiation of the osteoprogenitors. BMP-2 at all concentrations $(1,10$ and $100 \mathrm{ng} / \mathrm{ml})$ increased the number of bone nodules significantly by $42-83 \%$ over control OM alone. Similarly, using bone nodule formation by fetal rat mandibular cells, BMP-2 has been demonstrated to increase bone nodule formation at $50 \mathrm{ng} / \mathrm{ml}$ by more than 2 -fold. When dexamethasone is also added, the increase is even more pronounced [29]. In our study, we refrained from the use of dexamethasone, which has been controversial and could mask the effects induced by BMP-2 or doxycycline. We also determined that BMP-2 was able to induce expression of OCN in the human osteoprogenitor cells. Our data are consistent with results obtained using human bone marrow stromal cells, where BMP-2 at concentrations between 1-100 $\mathrm{ng} / \mathrm{ml}$ dose-dependently increases ALP activity. BMP-2, at $100 \mathrm{ng} / \mathrm{ml}$, also increases ALP mRNA expression and OCN protein expression [30].

Doxycycline at the lower concentrations of 10 and $50 \mu \mathrm{M}$ increased the number of mineralized bone nodules by $86 \%$ and $32 \%$, respectively. However, at the highest concentration of doxycycline tested, $100 \mu \mathrm{M}$, the number of nodules decreased when compared to OM alone. Doxycycline, at concentrations of 10 and $50 \mu \mathrm{M}$, also induced expression of OCN, whereas no OCN expression was observed in the controls. Other in vitro and in vivo studies have described the beneficial properties of doxycycline on bone formation [19, 31]. Using a different culture system, namely osteoblastic cell cultures differentiated from human bone marrow in the presence of dexamethasone, it has been found that doxycycline at concentrations of 2 and $10 \mu \mathrm{M}$ enhances deposition of minerals, as assessed semiquantitatively. At 10 and $20 \mu \mathrm{M}$, doxycycline also significantly increases ALP activity, but only after 21-35 days of culture which is after the ALP activity in the control cultures has peaked [31]. In these longterm cultures established from bone marrow, Gomes and Fernandes observe significant cytotoxicity after 7-35 days of treatment with doxycycline at concentrations of $48 \mu \mathrm{M}$ and higher [31]. While we did not measure cytotoxicity directly, we did not observe differences in the total protein content of treated cells as compared to controls. Moreover, cytotoxicity has not been reported for the lowest concentration of doxycycline used.

We demonstrated in this study that BMP-2, at all concentrations tested, and doxycycline, at low concentrations, similarly stimulated osteoblast differentiation as determined by osteocalcin expression and mineralization. This study is the first to show that doxycycline can stimulate osteoprogenitors derived from human cancellous bone towards differentiation of the osteoblastic phenotype in vitro which may account for its beneficial effects on bone formation observed in several different models. Furthermore, there was no distinguishable difference in nodule colony morphology between both treatment groups, which suggests that doxycycline treatment may trigger similar endpoint mineralization patterns to BMP-2 in vitro irrespective of its actual mechanistic action. BMPs, including BMP-2, have been shown to induce osteoblast differentiation [8-10]. Clinically, BMP-2 has been shown to stimulate the differentiation of osteoprogenitors and is employed to promote bone healing [11-14]. However, human recombinant BMP-2 is costly and side effects may include local swelling, erythema, and immune response [13]. BMPs act on a wide range of body tissues in a variety of manners, which are not well understood. Tetracyclines have been safely employed for decades as anitibiotics, even though gastrointestinal concerns have always been present. Subantimicrobial doses of doxycycline $(40 \mathrm{mg})$ are used to treat periodontitis and facial acne and are safe for use [32]. Pharmacological concentrations of doxycycline in serum reach $\sim 1 \mu \mathrm{M}$ at steady-state [33], levels that can be expected to be several fold higher in bone, as tetracyclines have long been shown to accumulate in the bone [34].

Therefore, even though BMP-2 is a successful stimulatory factor for osteoblast differentiation and the current clinical gold standard, doxycycline appears to be an equally efficacious alternative in vitro. Our study suggests that doxycycline could be considered as a viable alternative for the differentiation of osteoprogenitors into mature osteoblasts with the ability to form bone and therefore has significant clinical potential.

\section{ACKNOWLEDGEMENTS}

This research is supported by the Canadian Institutes of Health Research, Ottawa ON, Canada to GS.

\section{ABBREVIATIONS}

ALP $=$ Alkaline Phosphatase
BMP $=$ Bone Morphogenetic Protein;
GAPDH $=$ Glyceraldehyde-3-phosphate dehydrogenase
OCN $=$ Osteocalcin
OM $=$ Osteogenic Medium
PBS $=$ Phosphate-buffered saline


RT-PCR $=$ Reverse transcriptase-polymerase chain reaction

SM = Standard Medium

\section{REFERENCES}

[1] Kartsogiannis $\mathrm{V}, \mathrm{Ng} \mathrm{KW}$. Cell lines and primary cell cultures in the study of bone cell biology. Mol Cell Endocrinol 2004; 228: 79102.

[2] Ng AM, Saim AB, Tan KK, et al. Comparison of bioengineered human bone construct from four sources of osteogenic cells. J Orthop Sci 2005; 10: 192-9.

[3] Sakata Y, Ueno $\mathrm{T}$, Kagawa $\mathrm{T}$, et al. Osteogenic potential of cultured human periosteum-derived cells - a pilot study of human cell transplantation into a rat calvarial defect model. J Craniomaxillofac Surg 2006; 34: 461-5.

[4] Huang W, Yang S, Shao J, Li YP. Signaling and transcriptional regulation in osteoblast commitment and differentiation. Front Biosci 2007; 12: 3068-92.

[5] Seibel MJ. Biochemical markers of bone turnover: part I: biochemistry and variability. Clin Biochem Rev 2005; 26: 97-122.

[6] Declercq HA, Verbeeck RM, De Ridder LI, Schacht EH, Cornelissen MJ. Calcification as an indicator of osteoinductive capacity of biomaterials in osteoblastic cell cultures. Biomaterials 2005; 26 : 4964-74.

[7] Katagiri T, Takahashi N. Regulatory mechanisms of osteoblast and osteoclast differentiation. Oral Dis 2002; 8: 147-59.

[8] Cheng H, Jiang W, Phillips FM, et al. Osteogenic activity of the fourteen types of human bone morphogenetic proteins (BMPs). J Bone Joint Surg Am 2003; 85: 1544-52.

[9] Yamaguchi A, Komori T, Suda T. Regulation of osteoblast differentiation mediated by bone morphogenetic proteins, hedgehogs, and Cbfa1. Endocr Rev 2000; 21: 393-411.

[10] Koch H, Jadlowiec JA, Whalen JD, et al. Osteoblastic differentiation of human adult mesenchymal stem cells after through gene transfer of BMP-2 in the absence of dexamethasone. Z Orthop Ihre Grenzgeb 2005; 143: 684-90.

[11] Szpalski M, Gunzburg R. Recombinant human bone morphogenetic protein-2: a novel osteoinductive alternative to autogenous bone graft? Acta Orthop Belg 2005; 71: 133-48.

[12] Swiontkowski MF, Aro HT, Donell S, et al. Recombinant human bone morphogenetic protein-2 in open tibial fractures. A subgroup analysis of data combined from two prospective randomized studies. J Bone Joint Surg Am 2006; 88: 1258-65.

[13] Jones AL, Bucholz RW, Bosse MJ, et al. Recombinant human BMP-2 and allograft compared with autogenous bone graft for reconstruction of diaphyseal tibial fractures with cortical defects. A randomized, controlled trial. J Bone Joint Surg Am 2006; 88: 143141.

[14] Dimar JR, Glassman SD, Burkus KJ, Carreon LY. Clinical outcomes and fusion success at 2 years of single-level instrumented posterolateral fusions with recombinant human bone morphogenetic protein-2/compression resistant matrix versus iliac crest bone graft. Spine 2006; 31: 2534-9.

[15] Sasaki T, Ramamurthy NS, Golub LM. Tetracycline administration increases collagen synthesis in osteoblasts of streptozotocininduced diabetic rats: a quantitative autoradiographic study. Calcif Tissue Int 1992; 50: 411-9.

[16] Williams S, Wakisaka A, Zeng QQ, et al. Minocycline prevents the decrease in bone mineral density and trabecular bone in ovariectomized aged rats. Bone 1996; 19: 637-44.
[17] Bain S, Ramamurthy NS, Impeduglia $\mathrm{T}$, et al. Tetracycline prevents cancellous bone loss and maintains near-normal rates of bone formation in streptozotocin diabetic rats. Bone 1997; 21: 14753.

[18] Kaneko H, Sasaki T, Ramamurthy NS, Golub LM. Tetracycline administration normalizes the structure and acid phosphatase activity of osteoclasts in streptozotocin-induced diabetic rats. Anat Rec 1990; 227: 427-36.

[19] Duivenvoorden WCM, Vukmirovic-Popovic S, Lhotak S, et al. Doxycycline decreases tumor burden in a bone metastasis model of human breast cancer. Cancer Res 2002; 62: 1588-91.

[20] Metzger Z, Belkin D, Kariv N, Dotan M, Kfir A. Low-dose doxycycline inhibits bone resorption associated with apical periodontitis. Int Endod J 2008; 41: 303-9.

[21] Pytlik M, Folwarczna J, Janiec W. Effects of doxycycline on mechanical properties of bones in rats with ovariectomy-induced osteopenia. Calcif Tissue Int 2004; 75: 225-30.

[22] Chang CY, Yamada S. Evaluation of the regenerative effect of a $25 \%$ doxycycline-loaded biodegradable membrane for guided tissue regeneration. J Periodontol 2000; 71: 1086-93.

[23] Bhargava U, Bar-Lev M, Bellows CG, Aubin JE. Ultrastructural analysis of bone nodules formed in vitro by isolated fetal rat calvaria cells. Bone 1988; 9: 155-63.

[24] Pei W, Yoshimine Y, Heersche JN. Identification of dexamethasone-dependent osteoprogenitors in cell populations derived from adult human female bone. Calcif Tissue Int 2003; 72: 124-34.

[25] Sakaguchi Y, Sekiya I, Yagishita K, et al. Suspended cells from trabecular bone by collagenase digestion become virtually identical to mesenchymal stem cells obtained from marrow aspirates. Blood 2004; 104: 2728-35.

[26] Tuli R, Seghatoleslami MR, Tuli S, et al. A simple, high-yield method for obtaining multipotential mesenchymal progenitor cells from trabecular bone. Mol Biotechnol 2003; 23: 37-49.

[27] Robey PG, Termine JD. Human bone cells in vitro. Calcif Tissue Int 1985; 37: 453-60.

[28] Schliephake H, Bertram H, Lindenmaier W, Dauner M, Mayer H In vitro manipulation of primary human osteo-progenitor cells for tissue technological bone production. Mund Kiefer Gesichtschir 2000; 4: S470-3.

[29] Abe Y, Abe T, Aida Y, Hara Y, Maeda K. Follistatin restricts bone morphogenetic protein (BMP)-2 action on the differentiation of osteoblasts in fetal rat mandibular cells. J Bone Miner Res 2004; 19: 1302-7.

[30] Fromigue O, Marie PJ, Lomri A. Bone morphogenetic protein-2 and transforming growth factor-beta2 interact to modulate human bone marrow stromal cell proliferation and differentiation. J Cell Biochem 1998; 68: 411-26.

[31] Gomes PS, Fernandes MH. Effect of therapeutic levels of doxycycline and minocycline in the proliferation and differentiation of human bone marrow osteoblastic cells. Arch Oral Biol 2007; 52: 251-9.

[32] Preshaw PM, Hefti AF, Jepsen S, et al. Subantimicrobial dose doxycycline as adjunctive treatment for periodontitis. A review. J Clin Periodontol 2004; 31: 697-707.

[33] Caton JG. Evaluation of Periostat for patient management. Compend Contin Educ Dent 1999; 20: 451-6.

[34] Villanueva AR, Kujawa M, Mathews CH, Parfitt AM. Identification of the mineralization front: comparison of a modified toluidine blue stain with tetracycline fluorescence. Metab Bone Dis Relat Res 1983; 5: 41-5.

\section{(C) Eglence et al.; Licensee Bentham Open.}

This is an open access article licensed under the terms of the Creative Commons Attribution Non-Commercial License (http://creativecommons.org/licenses/by$\mathrm{nc} / 3.0 /$ ), which permits unrestricted, non-commercial use, distribution and reproduction in any medium, provided the work is properly cited. 